\title{
The Effect of Printing Parameters and Wood Surface Preparation on the Adhesion of Directly 3D-Printed PLA on Wood
}

\author{
Daša Krapež Tomec, Angela Balzano, Jure Žigon, Milan Šernek and Mirko Kariž \\ Department of Wood Science and Technology, Biotechnical Faculty, University of Ljubljana, Ljubljana, 1000, Slovenia \\ ${ }^{*}$ Corresponding Author: Mirko Kariž. Email: mirko.kariz@bf.uni-lj.si
}

Received: 13 October 2021 Accepted: 23 November 2021

\begin{abstract}
As additive manufacturing technologies advance, new opportunities are opening up for their application in the furniture industry. Wood remains one of the leading raw materials in the furniture industry; therefore, possible options for combining it with 3D printing have been researched. The bonding of 3D-printed polymer parts with wood or 3D printing with wood-plastic composites is already known, but in our research we attempted to directly 3D print polylactic acid (PLA) on wood surfaces. The effect of printing parameters, as well as the surface preparation of wood on the shear strength of the bond between wood and on-printed material was tested. Microscopic images of cross-sections of samples were analyzed. The results show that with a lower initial layer thickness $(0.1 \mathrm{~mm})$, a higher printing temperature $\left(220^{\circ} \mathrm{C}\right)$, and with the use of polyvinyl acetate (PVAc) primer on the wood surface before 3D printing, a higher bond strength (5.4 MPa) was achieved, but the values for the bond strength remain low compared to the conventional bonding of wood to wood with PVAc adhesive (around $10 \mathrm{MPa}$ ). Microscopy studies revealed barely visible penetration of PLA into the lumens of the wood cells. However, the PVAc adhesive used as primer penetrated more into the cell lumens and served as interface layer between deposited melted PLA and the wood, thus creating stronger joints.
\end{abstract}

\section{KEYWORDS}

FDM; direct 3D printing; adhesion; printing parameters; wood; PLA; PVAc

\section{Introduction}

Additive manufacturing, commonly referred to as three-dimensional (3D) printing, is a rapidly emerging technology but is currently limited by the dimensions of the final products due to limited printer sizes, build volume, available technologies, the required post-processing and the printing time, which increases significantly with the product volume and surface quality required [1]. Researchers aim to produce larger and faster 3D printers [2] that produce products with properties comparable to or superior to those of products produced using conventional technologies. At the moment, the implementation of Additive Manufacturing (AM) in production must be done with a clear understanding of the constraints, such as limited material options, relatively high machine and material costs, limitation of maximum build size and relatively low processing speeds [1]. Thus, it is envisaged that AM will complement, rather than replace, conventional production processes, with clear potential for hybrid solutions and structural reinforcement and repair [3].

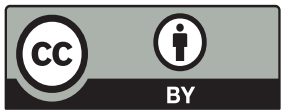

This work is licensed under a Creative Commons Attribution 4.0 International License, which permits unrestricted use, distribution, and reproduction in any medium, provided the original work is properly cited. 
The limitation of size and printing time could be solved by combining additive manufacturing technologies and conventional technologies. Thus, 3D printing is used to produce complex product parts, combined with simple parts produced by conventional machining, thereby reducing the production time and cost of the final product [4]. Assembly can be done with mechanical joints, adhesive bonding, or a combination of both [5] or by welding in the case of metal materials [6]. To sufficiently bond 3D-printed parts and other materials (e.g., polymers or wood), an optimal adhesive or surface preparation must be used [7].

Another possibility is direct 3D printing on products or subcomponents of the final products. Direct 3D printing on textiles for the production of wearable products [8,9] or printing of conductive materials to form circuit boards and electronic components is being explored [10]. In metal fabrication and metal construction, direct 3D printing is also used to repair damaged parts by applying new material to the damaged surface, followed by additional Computer Numerical Controlled (CNC) machining to achieve sufficient surface quality and accuracy [11].

Fused Deposition Modelling (FDM) 3D printing technology is widely used due to its availability, relatively simple 3D printers, and available materials. This technology allows the use of various thermoplastic polymers with a wide variety of properties. Thermoplastic polymers are melted in a nozzle, extruded, and deposited on the previous layer. This deposition technique creates temperature gradients and stresses that affect the interlayer strength and the strength of the entire product [12]. The temperature distribution between the extruded polymer filaments in the FDM process determines the bonding quality, integrity, and mechanical properties of the resulting prototypes $[12,13]$.

To achieve proper adhesion and strength of the product, the polymer must have a sufficiently low melt viscosity to fuse with the previous layer. Furthermore, the temperature of the previous layer is important: if it is too cold, the deposited material might solidify too fast and not wet the material properly. The same is important for direct printing on existing surfaces. It is difficult to heat the surface; thus, hot melted material is deposited to a cold surface, affecting wetting (contact and spread over the surface) and adhesion, thus creating additional stresses in the bonding layer. When $3 \mathrm{D}$ printing on textiles, in addition to the correct distance between printing nozzle and textile substrate, increased extrusion temperatures and reduced printing speeds $[8,14]$ or surface preparation and properties [15], a pre-coating is often required to improve adhesion.

In this research, the effect of printing parameters (nozzle temperature, thickness of the first layer) and surface preparation of the wood (use of a polyvinyl acetate (PVAc) adhesive layer as a primer) on the adhesion of direct 3D printing of polylactic acid (PLA) polymer on the surface of beech wood are investigated. This research aimed to evaluate the possibility of direct 3D printing on wood for use as 3Dprinted connectors or on furniture accessories. This innovation is also of interest for industrial applications in which polymer components could be 3D printed directly on the wood surface without the need for bonding it, thereby also reducing the use of screws, metal connectors and the number of assembly operations in the construction of furniture.

\section{Material and Methods}

\subsection{Direct 3D Printing}

A Creality CR10-V3 3D printer (Creality 3D Technology Co., Ltd., Shenzhen, China) with a direct extruder was used for direct printing on the wood surface. The printing layer thickness of the first layer varied between 0.1 to $0.3 \mathrm{~mm}$; the thickness of the rest of the layers was $0.2 \mathrm{~mm}$. The nozzle diameter was $0.4 \mathrm{~mm}$; the printing temperature for the first layer varied from 200 to $220^{\circ} \mathrm{C}$; the next layers were 
printed at $200^{\circ} \mathrm{C}$, and the bed temperature was at $30^{\circ} \mathrm{C}$. Samples were printed with solid layers with printing lines in a $45^{\circ} /-45^{\circ}$ raster angle (alternating each layer). Commercially available PLA filament (Plastika Trček, Slovenia; abbreviated as PT) with $1.75 \mathrm{~mm}$ diameter was used. The printer was modified with BL Touch, an auto bed levelling sensor (Creality 3D Technology Co., Ltd., Shenzhen, China), to detect the printing surface and to determine the wood thickness before printing, always using the same initial nozzle offset.

The 3D-printed model (rectangular shape/of $(20 \times 20 \times 10) \mathrm{mm})$ was designed in SolidWorks software (SolidWorks Corp., Massachusetts, USA) and exported to STL format. The STL model was sliced and prepared for 3D printing in Cura V4.10.0 software (Ultimaker, Utrecht, Netherlands). The printing temperature, the thickness of the first layer, and all printing parameters were set in Cura. Three solid layers were created on the top, walls and bottom, while the infill in the inner layers was $40 \%$. Fan cooling was set at $20 \%$ for the first layer and $100 \%$ for the next layers. The printing speed for the first layer was $20 \mathrm{~mm} / \mathrm{s}$ and $50 \mathrm{~mm} / \mathrm{s}$ for the rest of the cube.

Wooden lamellas were made of beech (Fagus sylvatica L.) wood, with a semi-radial orientation of wood fibers, a nominal density of $635 \mathrm{~kg} / \mathrm{m}^{3}$ and moisture content of $12 \%$.

Wooden lamellas $(250 \times 40 \times 40) \mathrm{mm}$ were planed before $3 \mathrm{D}$ printing to ensure a fresh, noncontaminated surface. Samples with pre-treated surfaces were thinly coated with commercial PVAc adhesive Mekol (Mitol, Sežana, Slovenia) at an application rate of $100 \mathrm{~g} / \mathrm{m}^{2}$ and left to dry overnight.

Wood lamellas were placed on the printer bed on an acrylic template to secure their position and prevent slipping during printing. The printer detected the wood lamellas thickness with the BL touch sensor and printed five cubes in a row simultaneously (Fig. 1). The wooden lamellas with printed samples were left to cool under room conditions and tested the next day.
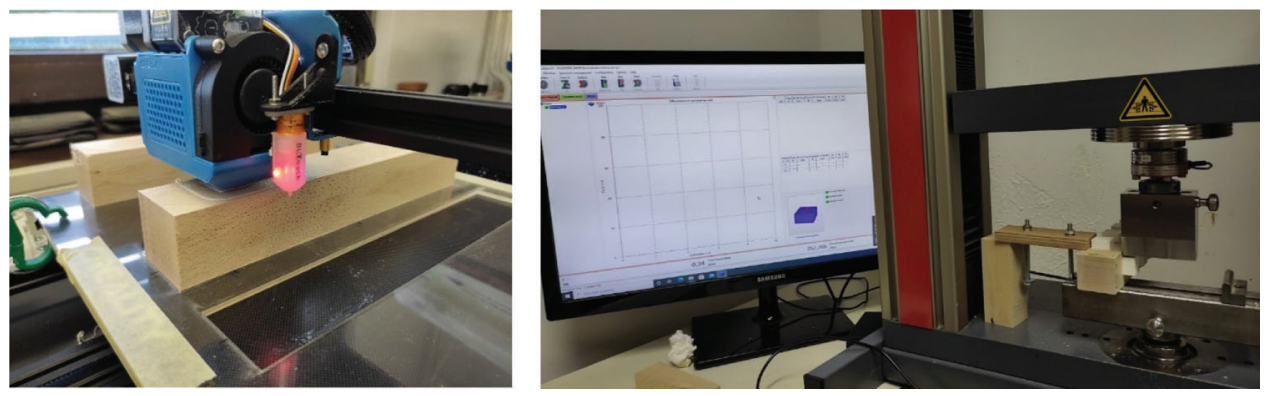

Figure 1: Setup for direct 3D printing on wood surfaces (left), test setup for compression bond shear test (right)

\subsection{Bond Shear Strength Testing}

The compression shear test (by modified standard SIST EN 392:1996 [16]) was used to determine the bond shear strength on the Z005 universal testing machine (ZwickRoell GmbH, Ulm, Germany). The loading speed was $2 \mathrm{~mm} / \mathrm{min}$, and the samples were loaded until failure. Bond shear strength was calculated from the maximum force and measured shear area dimensions of the 3D-printed rectangular solid, and the percentage of wood failure was evaluated. Ten specimens (printed rectangular solids) were prepared for each tested condition (Table 1). In preliminary research, samples with a $0.3 \mathrm{~mm}$ thick first layer showed very low strengths; thus, only samples with planed surfaces were selected and tested for this layer thickness. The group with a $0.3 \mathrm{~mm}$ layer thickness and PVAc as the primer was not prepared and tested. 
Table 1: Group markings for varied parameters: printing temperature, first layer thickness and surface preparation

\begin{tabular}{llll}
\hline Surface preparation & First layer printing temperature $\left({ }^{\circ} \mathrm{C}\right)$ & First layer thickness $(\mathrm{mm})$ & Group marking \\
\hline Planed & 200 & 0.1 & $200-0.1$ \\
Planed + PVAc & 200 & 0.1 & $200-0.1-\mathrm{P}$ \\
Planed & 200 & 0.2 & $200-0.2$ \\
Planed + PVAc & 200 & 0.2 & $200-0.2-\mathrm{P}$ \\
Planed & 200 & 0.3 & $200-0.3$ \\
Planed & 210 & 0.1 & $210-0.1$ \\
Planed + PVAc & 210 & 0.1 & $210-0.1-\mathrm{P}$ \\
Planed & 210 & 0.2 & $210-0.2$ \\
Planed + PVAc & 210 & 0.2 & $210-0.2-\mathrm{P}$ \\
Planed & 210 & 0.3 & $210-0.3$ \\
Planed & 220 & 0.1 & $220-0.1$ \\
Planed + PVAc & 220 & 0.1 & $220-0.1-\mathrm{P}$ \\
Planed & 220 & 0.2 & $220-0.2$ \\
Planed + PVAc & 220 & 0.2 & $220-0.2-\mathrm{P}$ \\
Planed & 220 & 0.3 & $220-0.3$ \\
\hline
\end{tabular}

\subsection{Microscopic Images}

\subsubsection{Transmission Light Microscopy}

Sub-samples were taken from each wooden lamella to be processed for a light microscopy observation. Sub-samples were dehydrated in ethanol series (70, 90, 95, and 100\%) and bio-clear (d-limonene) and afterwards embedded in paraffin. The embedded samples were cut with a semi-automatic rotary microtome RM 2245 (Leica, Nussloch, Germany) to obtain thin cross-sections ( $9 \mu \mathrm{m}$ thick) that were flattened on slides pre-treated with albumin. Slides were dried at $70^{\circ} \mathrm{C}$ for $30 \mathrm{~min}$ and cleaned of residual paraffin by washing with bio-clear and ethanol and afterwards stained with an aqueous solution of safranin and astra blue. Slides were permanently mounted on glass slides in Euparal (BioQuip, Rancho Dominguez, California, USA). Sections were observed with Eclipse 800 light microscope (Nikon, Tokyo, Japan), and microphotographs were taken using a DS-Fil digital camera with the NIS-Elements BR 3 image analysis system (Nikon Instruments Inc., Melville, NY, USA).

\subsubsection{Scanning Electron Microscopy (SEM)}

A scanning electron microscope Quanta 250 (FEI, Thermo Fisher Scientific, Waltham, MA, USA) was used to visually assess the contact surface between beech wood and the 3D-printed PLA layer. The samples were sprayed with a conductive gold layer prior to SEM observations. Images of the area on the cross-section of the samples were acquired in a high vacuum $\left(1.56 \times 10^{-2} \mathrm{~Pa}\right)$; the electron source voltage was $5.0 \mathrm{kV}$, and the spot size was $4.0 \mathrm{~nm}$. During the acquisition of each image, the time of the beam transition through the sample was $45 \mu \mathrm{s}$. 


\section{Results and Discussion}

The lowest bond shear strengths were measured for samples printed with the thickest first layer $(0.3 \mathrm{~mm})$ and the highest for samples printed with the thinnest first layer $(0.1 \mathrm{~mm})$ (Fig. 2). The reason could be that when the first layer thickness is thinner, the nozzle is closer to the wood surface during extrusion so that the extruded material is pressed to the wood surface with a higher extrusion force. Moreover, the melted polymer has less time to cool and, therefore, can flow better onto the wood surface and achieve better wetting (contact and spread over the surface) and mechanical interlocking. With a thicker first layer setting, the nozzle is further away from the wood and, instead of pushing the melted polymer on wood, it could spread sideways/laterally.

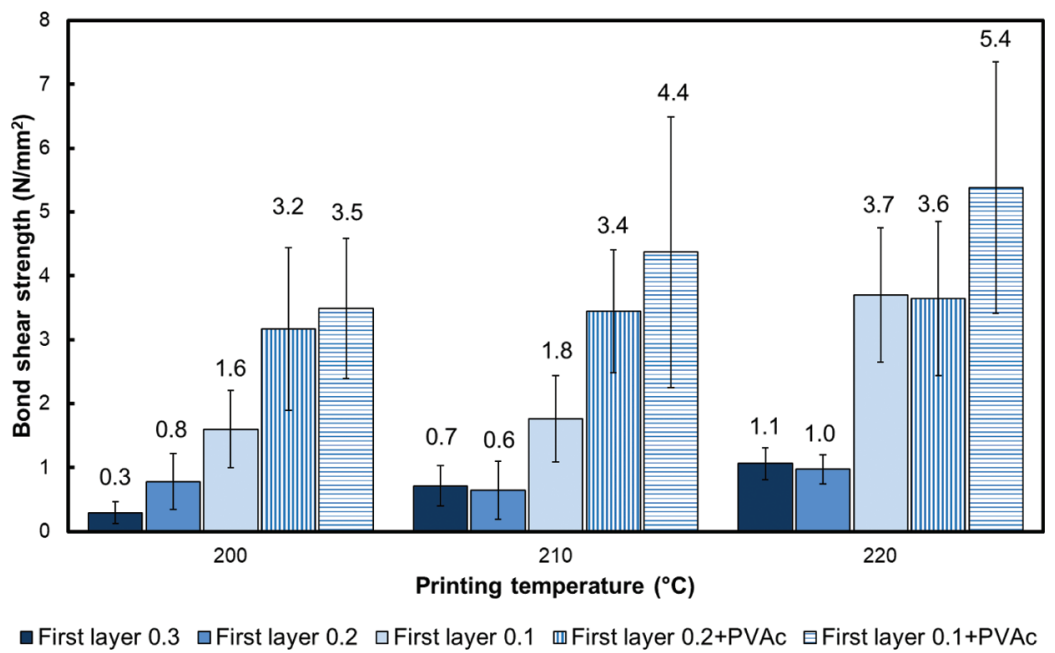

Figure 2: Bond shear strength at different printing temperatures and thickness of the first layer

For parts produced by FDM, the adhesion between the first printed layer and the printing bed is crucial, as it provides the basis for the subsequent layers [17]. Usually, it is recommended to heat the bed's surface close to the glass transition temperature of the polymer. In this case, good distribution of the melted polymer, good flow, and good adhesion are obtained. In the case of our printing on the wood surface, the surface of the wood was at room temperature and far from the glass transition temperature of PLA (from 50 to $80^{\circ} \mathrm{C} \mathrm{[18]).}$ The melted polymer (at about 200 to $220^{\circ} \mathrm{C}$ ) was deposited to the colder surface, cooled rapidly, and solidified upon contact with the colder surface, preventing proper flow and penetration.

The measured bond shear strengths are still low compared to the usual bond strengths when bonding wood to wood with commercial adhesives, for which the strengths of 10 to $15 \mathrm{MPa}$ can be reached $[19,20]$. When bonding 3D-printed parts to wood with adhesive, the strength depends on the properties of 3D-printed parts and the adhesives used. For acrylonitrile butadiene styrene (ABS) printed samples, for example, the bond shear strength ranges from 1.8 to 5.3 MPa [5] but could be improved to 3.7 MPa for PLA or 4.8 MPa for ABS with the surface treatment of polymer with atmospheric plasma [7].

The evaluation of the percentage of wood failure (ratio of the fracture area in the wood to the total shear area) shows where the failure occurred (Table 2): mostly in the bond layer (adhesion break) and in some samples in the wood (cohesion break in the wood). The wood failure occurred in 3D-printed samples with the lowest initial layer thickness $(0.1 \mathrm{~mm})$ and in the samples with PVAc as the primer. The percentage of failure in wood was the highest for the samples with $0.1 \mathrm{~mm}$ thick first layer and PVAc primer and increased with printing temperature. The 3D-printed material never failed, indicating that its shear strength was higher than that of the bond/compound. 
Table 2: Average percentage of wood failure (\%)

\begin{tabular}{|c|c|c|c|c|c|c|c|c|c|c|}
\hline & \multicolumn{2}{|c|}{$\begin{array}{c}\text { First layer } \\
\text { thickness } \\
0.3 \\
\end{array}$} & \multicolumn{2}{|c|}{$\begin{array}{c}\text { First layer } \\
\text { thickness } \\
0.2 \\
\end{array}$} & \multicolumn{2}{|c|}{$\begin{array}{c}\text { First layer } \\
\text { thickness } \\
0.1 \\
\end{array}$} & \multicolumn{2}{|c|}{$\begin{array}{c}\text { First layer } \\
\text { thickness } 0.2+ \\
\text { PVAc } \\
\end{array}$} & \multicolumn{2}{|c|}{$\begin{array}{c}\text { First layer } \\
\text { thickness } 0.1+ \\
\text { PVAc }\end{array}$} \\
\hline $\begin{array}{l}\text { Printing } \\
\text { temperature }\left({ }^{\circ} \mathrm{C}\right)\end{array}$ & Average & $\begin{array}{l}\text { St. } \\
\text { dev. }\end{array}$ & Average & $\begin{array}{l}\text { St. } \\
\text { dev. }\end{array}$ & Average & $\begin{array}{l}\text { St. } \\
\text { dev. }\end{array}$ & Average & $\begin{array}{l}\text { St. } \\
\text { dev. }\end{array}$ & Average & $\begin{array}{l}\text { St. } \\
\text { dev. }\end{array}$ \\
\hline 200 & 0 & 0 & 0 & 0 & 0 & 0 & 10 & 20 & 20 & 30 \\
\hline 210 & 0 & 0 & 0 & 0 & 0 & 0 & 0 & 0 & 40 & 50 \\
\hline 220 & 0 & 0 & 0 & 0 & 10 & 10 & 10 & 20 & 80 & 10 \\
\hline
\end{tabular}

Microscopic images show the arrangement of the printing lines in the first layer. The setting in the slicing software was set to $100 \%$ infill in the first layer, but there visible gaps and voids remain in the printed material. This could be improved in printing settings by increasing the infill of the first layer. If the first layer were over-extruded (infill set for more than 100\%), more material would be pushed into these voids, reducing its volume and increasing the contact surface between PLA and wood. In the majority of samples, the bottom of printing lines is almost flat, except in cases in which larger sliced open wood cells (lumens) were directly on the surface, and the melted polymer flowed into this cavity (Fig. 3).

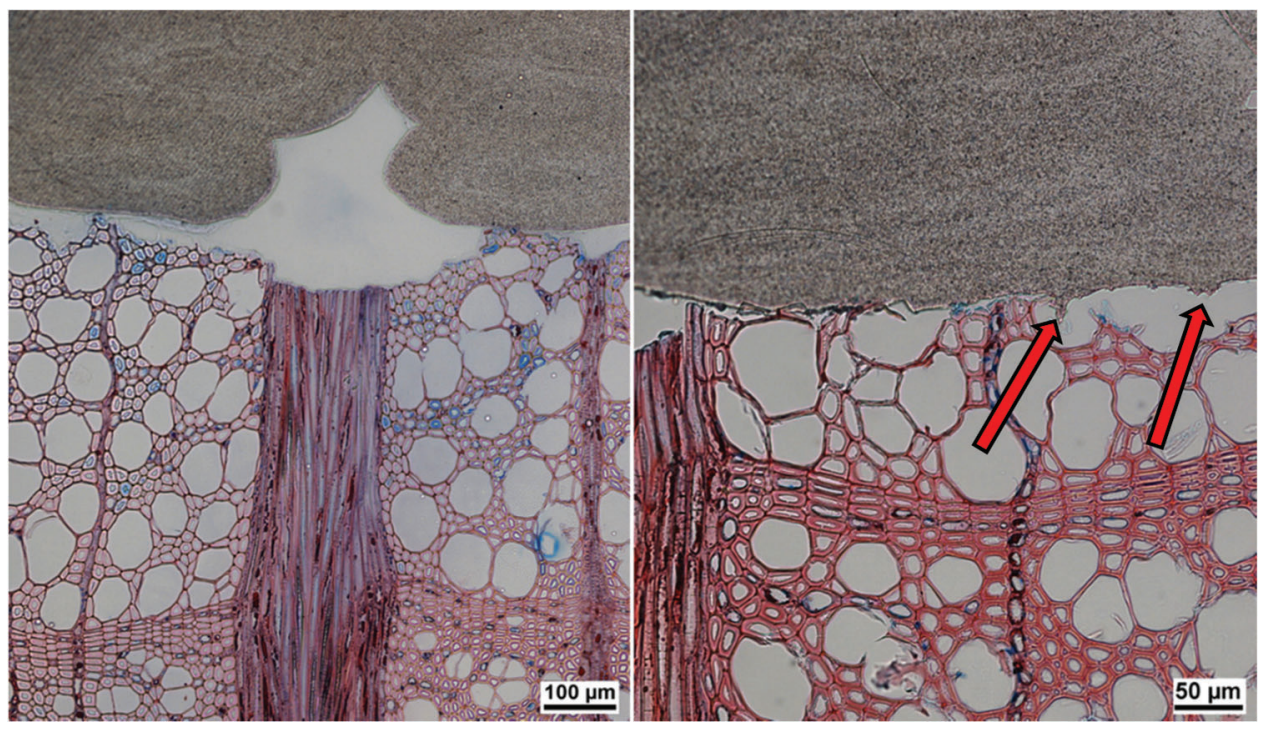

Figure 3: Left: Sample printed with $210^{\circ} \mathrm{C}, 0.2 \mathrm{~mm}$ first layer, at $10 \times$ magnification; Right: Sample printed with $200^{\circ} \mathrm{C}, 0.1 \mathrm{~mm}$ first layer, at $20 \times$ magnification. Arrows indicate possible penetration of polymer into the cut open cell lumen

Fig. 4 shows SEM photos of the bond between 3D-printed PLA and wood coated with PVAc, which serves as a primer. The penetration of PVAc adhesive into the wood cell lumens is visible and marked with white arrows. This penetration and mechanical interlocking greatly improve adhesion. The thickness of this cured PVAc layer is about 50-70 $\mu \mathrm{m}$ (marked with red two-sided arrows) and thick enough to prevent direct contact of the 3D-printed material with the wood. The 3D-printed PLA is bonded to the cured PVAc layer, marked with thin yellow arrows. PVAc thus acts as an interface layer between two different materials and improves the strength of the joint. The edges between the deposited PLA and 
PVAc are rounded, which indicates that the cured thermoplastic PVAc also melted/softened and bonded with the deposited material during the depositing of hot melted PLA. This suggests that some sort of "wetting" of the material occurred. The setting in the slicing software was set to $100 \%$ infill in the first layer; the surface was completely covered with extruded material. However, in the cross-section in the microscopic image (Fig. 4), there are still voids between two parallel printing (extruded) lines (marked with middle yellow arrow). Supposing the first layer would be over-extruded (more than 100\%), more material would likely be pushed into these voids, increasing the contact surface between PLA and wood.

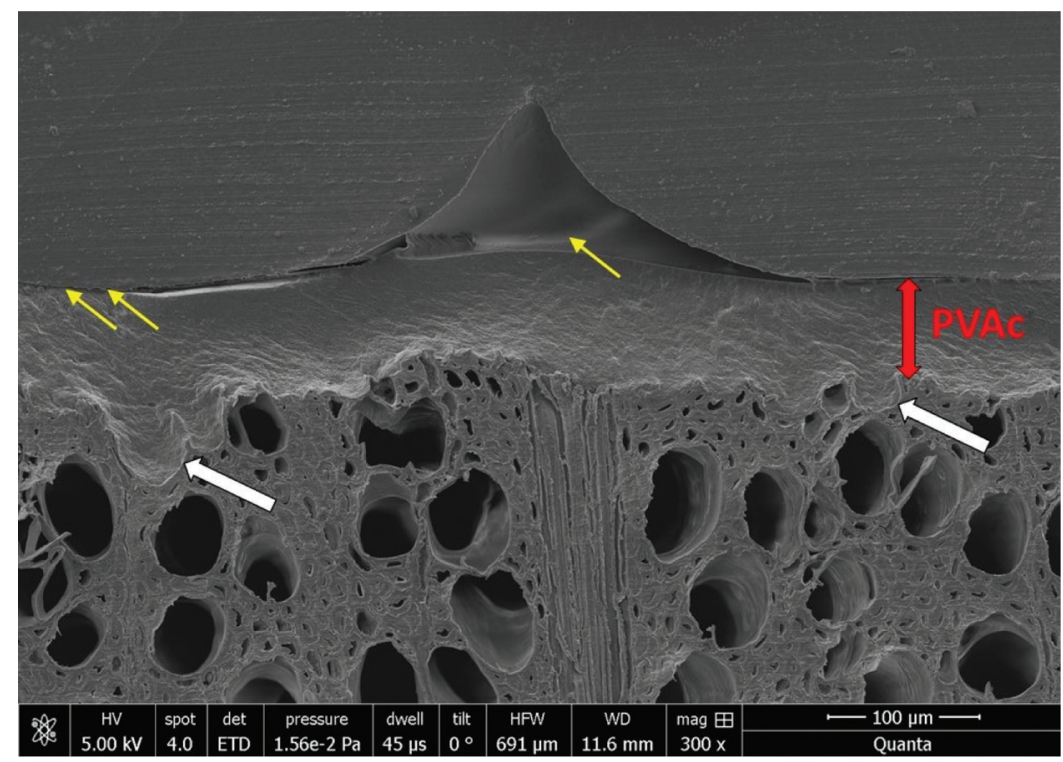

Figure 4: SEM image of a sample printed on surface with PVAc as primer with $200^{\circ} \mathrm{C}, 0.2 \mathrm{~mm}$ first layer, at $300 \times$ magnification

The samples with PLA directly printed on wood (without PVAc as a primer) were difficult to prepare, and most fell apart during sample preparation (cutting on the microtome and preparing for SEM analysis). The bonds were too weak to withstand the forces during cutting and due to the vacuum in SEM. Fig. 5 shows one of the samples in which a crack developed between the wood and the printed material, marked with thin yellow arrows. There is also almost no penetration of PLA into the cell lumens of the wood. The edges of deposited PLA are not rounded as in the samples with PVAc as a primer, which is a sign of less "wetting" of the wood with PLA. The sample in Fig. 5 was printed at a higher temperature $\left(220^{\circ} \mathrm{C}\right)$ than the sample in Fig. $4\left(200^{\circ} \mathrm{C}\right)$. Therefore, one would expect a lower viscosity of the extruded PLA, thus more wetting and a larger contact area on each printed strand to wood. However, the images do not completely confirm this assumption, because the sample in Fig. 4 was cut perpendicular to wood fibers and at the angle of $45^{\circ}$ to printing lines and, therefore, the contact area (PLA strands-wood) looks wider than in Fig. 5, where the cut was aligned.

Melted PLA was deposited directly onto the wood surface at room temperature, resulting in a high temperature gradient, rapid cooling and solidification of the melted polymer. This affected the flow of the melted polymer and penetration into the surface, reducing mechanical interlocking and even causing internal stress. In FDM printing for optimal adhesion to the previous layer (or printing bed), the temperature of the deposited material needs to be sufficiently above the glass transition temperature $\left(T_{g}\right)$ for a sufficient time so that higher mobility of the polymer segments leads to an arrangement of the polymer chains with the build plate surface, minimizing the thermal energy between them, and increasing 
adhesion [21]. Some technologies even use laser heating synchronized with the printing path prior to deposition, radiation or hot air to heat the previous layers and increase interfacial adhesion to improve the strength of printed materials and reduce mechanical anisotropy [22]. Slow cooling, annealing, stretching, or nucleating agents increase the crystallinity of PLA and thus its strength and modulus, as does increasing its molecular weight. However, the printing speed must be reduced in these cases [23]. In addition, if the nozzle temperature is too high, the dimensional accuracy of the print suffers due to migration of the polymer melt [21] or even polymer degradation.

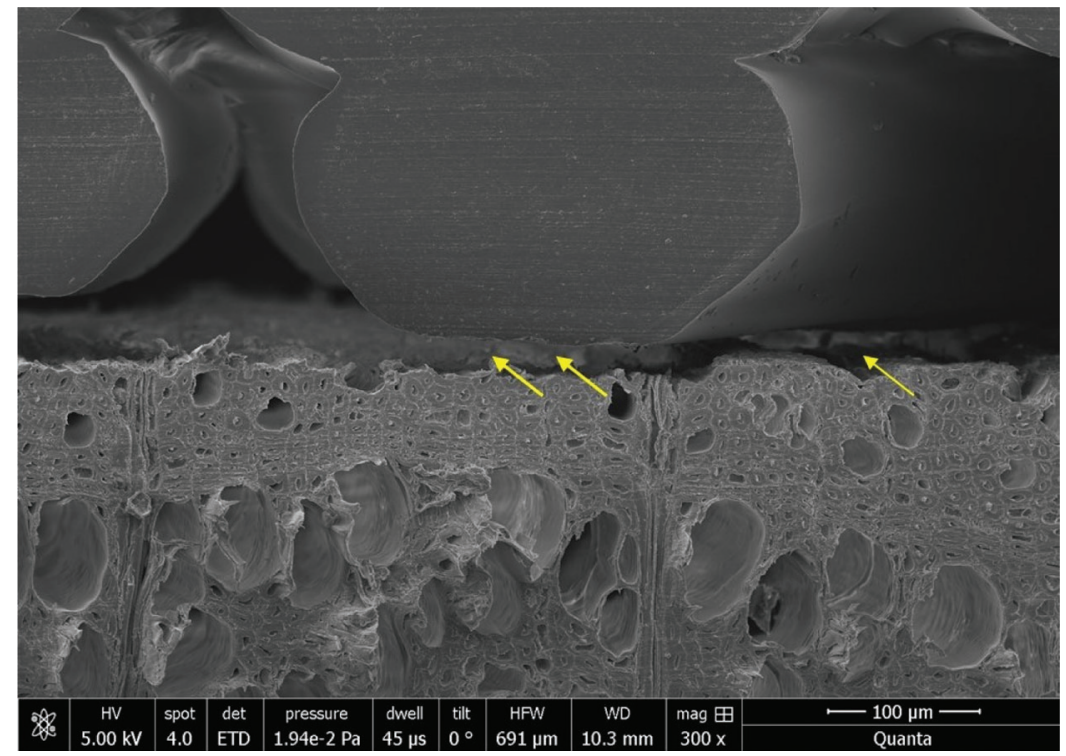

Figure 5: SEM photo of samples printed on surface with $220^{\circ} \mathrm{C}, 0.2 \mathrm{~mm}$ first layer, at $300 \times$ magnification

Samples with a layer of PVAc adhesive applied on their surfaces exhibited higher bond strengths. PVAc has good adhesion to wood and acts as a layer between hydrophilic wood and relatively hydrophobic PLA polymer [24]. The problem of compatibility of natural fibers/particles and polymers is well known in the production of wood-plastic composites, for which it is necessary to create a good interface between the polymer and the natural fibers. This can be achieved by the chemical treatment of the fiber surface or by adding a suitable coupling agent [25].

\section{Conclusions}

The results show that direct 3D printing of PLA on wood surfaces is possible using a simple FDM printer, but the bond strength needs to be considered. The bond shear strength of the printed rectangular volumes on wood was influenced by the observed printing settings: the thickness of the first layer, the printing temperature of the first layer, and the preparation of the wood surface.

To achieve satisfactory bond strengths for some applications, the small thickness of the first layer $(0.1 \mathrm{~mm})$, higher extruding temperature $\left(220^{\circ} \mathrm{C}\right)$, and appropriate surface preparation (like using PVAc as a primer) should be used.

Further investigations on other printing settings (printing speed, different materials, heating of the wood surface etc.) and on the long-term behavior of these joints and are needed to understand the adhesion of direct $3 \mathrm{D}$ printing on wood and its potential for industrial application better. 
Acknowledgement: The authors acknowledge the support of the Slovenian Research Agency (ARRS) within the Framework of Research Program P4-0015.

Funding Statement: The authors received no specific funding for this study.

Conflicts of Interest: The authors declare that they have no conflicts of interest to report regarding the present study.

\section{References}

1. Ahuja, B., Karg, M., Schmidt, M. (2016). Additive manufacturing in production: Challenges and opportunities. Laser 3D manufacturing II, Vol. 9353, pp. 935304. International Society for Optics and Photonics. DOI $10.1117 / 12.2082521$.

2. Zastrow, M. (2020). THE NEW 3D PRINTING Researchers are developing techniques to print faster, bigger and weirder. Nature, 578(7793), 20-24. DOI 10.1038/d41586-020-00271-6.

3. Buchanan, C., Gardner, L. (2019). Metal 3D printing in construction: A review of methods, research, applications, opportunities and challenges. Engineering Structures, 180, 332-348. DOI 10.1016/j.engstruct.2018.11.045.

4. Karayel, E., Bozkurt, Y. (2020). Additive manufacturing method and different welding applications. Journal of Materials Research and Technology, 9(5), 11424-11438. DOI 10.1016/j.jmrt.2020.08.039.

5. Kariz, M., Kuzman, M. K., Sernek, M. (2016). Adhesive bonding of 3D-printed ABS parts and wood. Journal of Adhesion Science and Technology, 31(15), 1683-1690. DOI 10.1080/01694243.2016.1268414.

6. Karayel, E., Bozkurt, Y. (2020). Additive manufacturing method and different welding applications. Journal of Materials Research and Technology, 9(5), 11424-11438. DOI 10.1016/j.jmrt.2020.08.039.

7. Kariž, M., Krapež Tomec, D., Dahle, S., Kitek Kuzman, M., Šernek, M. et al. (2021). Effect of sanding and plasma treatment of 3D-printed parts on bonding to wood with PVAc adhesive. Coatings, 13, 1-16. DOI 10.3390/ polym13081211.

8. Hashemi Sanatgar, R., Campagne, C., Nierstrasz, V. (2017). Investigation of the adhesion properties of direct 3D printing of polymers and nanocomposites on textiles: Effect of FDM printing process parameters. Applied Surface Science, 403, 551-563. DOI 10.1016/j.apsusc.2017.01.112.

9. Malengier, B., Hertleer, C., van Langenhove, L., Cardon, L. (2017). 3D printing on textiles: testing of adhesion. International Conference on Intelligent Textiles and Mass Customisation.

10. Espera, A. H., Dizon, J. R. C., Chen, Q., Advincula, R. C. (2019). 3D-printing and advanced manufacturing for electronics. Progress in Additive Manufacturing, 4(3), 245-267. DOI 10.1007/s40964-019-00077-7.

11. Ren, L., Padathu, A. P., Ruan, J., Sparks, T., Liou, F. W. (2006). Three dimensional die repair using a hybrid manufacturing system. Proceedings of the 17th Solid Freeform Fabrication Symposium, pp. 14-16. Austin, USA.

12. Moumen, A. E., Tarfaoui, M., Lafdi, K., Tarfaoui, M., Lafdi, K. (2019). Modelling of the temperature and residual stress fields during 3D printing of polymer composites. International Journal of Advanced Manufacturing Technology, 104(5-8), 1661-1676. DOI 10.1007/s00170-019-03965-y.

13. Zhou, Y., Nyberg, T., Xiong, G., Liu, D. (2016). Temperature analysis in the fused deposition modeling process. 2016 3rd International Conference on Information Science and Control Engineering, IEEE, pp. 678-682, DOI 10.1109/ICISCE.2016.150.

14. Gorlachova, M., Mahltig, B. (2021). 3D-printing on textiles-An investigation on adhesion properties of the produced composite materials. Journal of Polymer Research, 28(6), 297. DOI 10.1007/s10965-021-02567-1.

15. Mpofu, N. S., Mwasiagi, J. I., Nkiwane, L. C., Njuguna, D. (2019). Use of regression to study the effect of fabric parameters on the adhesion of 3D printed PLA polymer onto woven fabrics. Fashion and Textiles, 6(1), 24. DOI 10.1186/s40691-019-0180-6.

16. SIST EN 392:1996 (1996). Glued laminated timber-Shear test of glue lines. 
17. Spoerk, M., Gonzalez-Gutierrez, J., Sapkota, J., Schuschnigg, S., Holzer, C. (2018). Effect of the printing bed temperature on the adhesion of parts produced by fused filament fabrication. Plastics Rubber and Composites, 47(1), 17-24. DOI 10.1080/14658011.2017.1399531.

18. Kariz, M., Sernek, M., Obućina, M., Kuzman, M. K. (2018). Effect of wood content in FDM filament on properties of 3D printed parts. Materials Today Communications, 14(1), 135-140. DOI 10.1016/j.mtcomm.2017.12.016.

19. Iždinský, J., Reinprecht, L., Sedliačik, J., Kúdela, J., Kučerová, V. (2020). Bonding of selected hardwoods with PVAc adhesive. Applied Sciences, 11(1), 67. DOI 10.3390/app11010067.

20. Zigon, J., Pizzi, A., Zhang, H., Sega, B., Cop, M. et al. (2015). The influence of heat and chemical treatments of beech wood on the shear strength of welded and UF bonded specimens. European Journal of Wood and Wood Products, 73(5), 685-687. DOI 10.1007/s00107-015-0930-0.

21. Bhagia, S., Bornani, K., Agarwal, R., Satlewal, A., Durkovič, J. et al. (2021). Critical review of FDM 3D printing of PLA biocomposites filled with biomass resources, characterization, biodegradability, upcycling and opportunities for biorefineries. Applied Materials Today, 24(8), 101078. DOI 10.1016/j.apmt.2021.101078.

22. Ravi, A. K., Deshpande, A., Hsu, K. H. (2016). An in-process laser localized pre-deposition heating approach to inter-layer bond strengthening in extrusion based polymer additive manufacturing. Journal of Manufacturing Processes, 24(1-3), 179-185. DOI 10.1016/j.jmapro.2016.08.007.

23. Perego, G., Glan, D., Cella, C., Bastloll, N. S. P. A. (1996). Effect of molecular weight and crystallinity on poly (lactic acid) mechanical properties introduction. Journal of Applied Polymer Science, 59, 37-43. DOI 10.1002/ (ISSN)1097-4628.

24. Baran, E. H., Erbil, H. Y. (2019). Surface modification of 3D printed PLA objects by fused deposition modeling: A review. Colloids Interfaces 2019, 3(2), 43. DOI 10.3390/colloids3020043.

25. Mazzanti, V., Malagutti, L., Mollica, F. (2019). FDM 3D printing of polymers containing natural fillers: A review of their mechanical properties. Polymers, 11(7), 1094. DOI 10.3390/polym11071094. 